\title{
Differences in renal hemodynamics and renin secretion between patients with unifocal and multifocal fibromuscular dysplasia
}

Citation for published version (APA):

van Twist, D. J. L., de Heer, P. W. M., Houben, A. J. H. M., de Haan, M. W., de Leeuw, P. W., \& Kroon, A. A. (2018). Differences in renal hemodynamics and renin secretion between patients with unifocal and multifocal fibromuscular dysplasia. Journal of Hypertension, 36(8), 1729-1735.

https://doi.org/10.1097/HJH.0000000000001755

Document status and date:

Published: 01/08/2018

DOI:

10.1097/HJH.0000000000001755

Document Version:

Publisher's PDF, also known as Version of record

Document license:

Taverne

Please check the document version of this publication:

- A submitted manuscript is the version of the article upon submission and before peer-review. There can be important differences between the submitted version and the official published version of record.

People interested in the research are advised to contact the author for the final version of the publication, or visit the DOI to the publisher's website.

- The final author version and the galley proof are versions of the publication after peer review.

- The final published version features the final layout of the paper including the volume, issue and page numbers.

Link to publication

\footnotetext{
General rights rights.

- You may freely distribute the URL identifying the publication in the public portal. please follow below link for the End User Agreement:

www.umlib.nl/taverne-license

Take down policy

If you believe that this document breaches copyright please contact us at:

repository@maastrichtuniversity.nl

providing details and we will investigate your claim.
}

Copyright and moral rights for the publications made accessible in the public portal are retained by the authors and/or other copyright owners and it is a condition of accessing publications that users recognise and abide by the legal requirements associated with these

- Users may download and print one copy of any publication from the public portal for the purpose of private study or research.

- You may not further distribute the material or use it for any profit-making activity or commercial gain

If the publication is distributed under the terms of Article 25fa of the Dutch Copyright Act, indicated by the "Taverne" license above, 


\title{
Differences in renal hemodynamics and renin secretion between patients with unifocal and multifocal fibromuscular dysplasia
}

\author{
Daan J.L. van Twist ${ }^{a, b, c}$, Pieter W.M. de Heer ${ }^{a, b}$, Alfons J.H.M. Houben ${ }^{a, b}$, Michiel W. de Haan ${ }^{d}$, \\ Peter W. de Leeuw ${ }^{a, b, c}$, and Abraham A. Kroon ${ }^{a, b}$
}

\begin{abstract}
Objective: Fibromuscular dysplasia (FMD) can be classified in a multifocal and a unifocal subtype. As unifocal FMD generally leads to more severe hypertension at younger age, we hypothesized that renal hemodynamics are more disturbed in unifocal renal artery FMD as compared with multifocal FMD, leading to increased renin secretion.
\end{abstract}

Methods: We measured renal blood flow $\left({ }^{133}\right.$ Xenon washout method), renin secretion, and glomerular filtration rate per kidney in 101 patients with FMD (26 unifocal and 75 multifocal), all off medication and prior to balloon angioplasty.

Results: We found that renal blood flow and glomerular filtration were substantially lower in kidneys with unifocal FMD as compared with multifocal FMD. In the affected kidney from patients with unilateral FMD for example, mean renal blood flow was $173 \pm 77$ in unifocal vs. $244 \pm 79 \mathrm{ml} / 100 \mathrm{~g}$ kidney/min in multifocal FMD $(P=0.013)$. Moreover, lateralization in renin secretion was only observed in a subset of patients with unifocal FMD, but not in any of the patients with multifocal FMD.

Conclusion: These findings suggest that the impact of unifocal FMD lesions on the kidney is more severe, resulting in a classical pattern of renovascular hypertension. In multifocal FMD, however, renal blood flow is more preserved, local renin secretion is not increased, and the association between renin levels and blood pressure is inverse. These differences may explain the often more severe clinical presentation and higher success rate of revascularization in unifocal FMD, but also suggest that the pathophysiological mechanisms leading to hypertension may differ between these two disease entities.

Keywords: fibromuscular dysplasia, kidney, reninangiotensin system, renovascular hypertension

Abbreviations: 24-h ABPM, 24-h ambulatory blood pressure measurement; APRC, active plasma renin concentration; ARAS, atherosclerotic renal artery stenosis; eGFR, estimated glomerular filtration rate; FMD, fibromuscular dysplasia; MRBF, mean renal blood flow; RSR, renin secretion rate

\section{INTRODUGTION}

$\mathrm{F}$ ibromuscular dysplasia (FMD) is a heterogenous group of nonatherosclerotic, noninflammatory vascular diseases that are a common cause of renovascular hypertension [1,2]. Two major FMD-entities can be distinguished by angiographic evaluation: the multifocal form, with its typical string-of-beads pattern, and the unifocal form, presenting as a single focal stenosis (Fig. 1) [3,4]. Histologically, the medial layer of the vessel wall is affected in multifocal FMD, whereas the intima or adventitia is affected in unifocal FMD [5,6]. Furthermore, several differences in clinical characteristics have been demonstrated: patients with unifocal FMD are more often male (31 vs. 17\%) and are generally diagnosed with hypertension at a younger age (26 vs. 40 years) and with a higher blood pressure (BP) (157/ 97 vs. 146/88 mmHg) [4]. Moreover, hypertension cure rates following balloon angioplasty are higher in unifocal FMD $[4,7]$. Based on these clinical, angiographic, and histopathological differences, it appears plausible that the effect on the kidney differs between unifocal and multifocal FMD. Previously, we demonstrated in a cohort of patients with multifocal FMD that renal blood flow and glomerular filtration are more or less preserved and that renin secretion is not increased [8,9]. Data on renal hemodynamics and renin secretion in patients with unifocal FMD, however, are lacking. Given the earlier and more severe clinical presentation with a better response to balloon angioplasty, we hypothesized that renal hemodynamics are more disturbed in unifocal FMD, leading to increased renin secretion. Therefore, we studied renal blood flow, glomerular filtration, and renin secretion in a cohort of patients with previously untreated

\footnotetext{
Journal of Hypertension 2018, 36:1729-1735

a Department of Internal Medicine, ${ }^{\mathrm{b}}$ CARIM School for Cardiovascular Diseases, Maastricht University Medical Centre (MUMC+), Maastricht, 'Department of Internal Medicine, Zuyderland Medical Centre, Geleen/Heerlen and ${ }^{\mathrm{d} D e p a r t m e n t}$ of Radiology, Maastricht University Medical Centre (MUMC+), Maastricht, The Netherlands

Correspondence to Dr Daan J.L. van Twist, MD, PhD, Department of Internal Medicine, Zuyderland Medical Centre, PO box 5500, 6130 MB Sittard, The Netherlands. Tel: +31 88576 6555; fax: +31 88459 7983;

e-mail: d.vantwist@zuyderland.nl

Received 7 December 2017 Revised 1 February 2018 Accepted 13 March 2018 J Hypertens 36:1729-1735 Copyright (C) 2018 Wolters Kluwer Health, Inc. All rights reserved.

DOI:10.1097/HJH.0000000000001755
} 

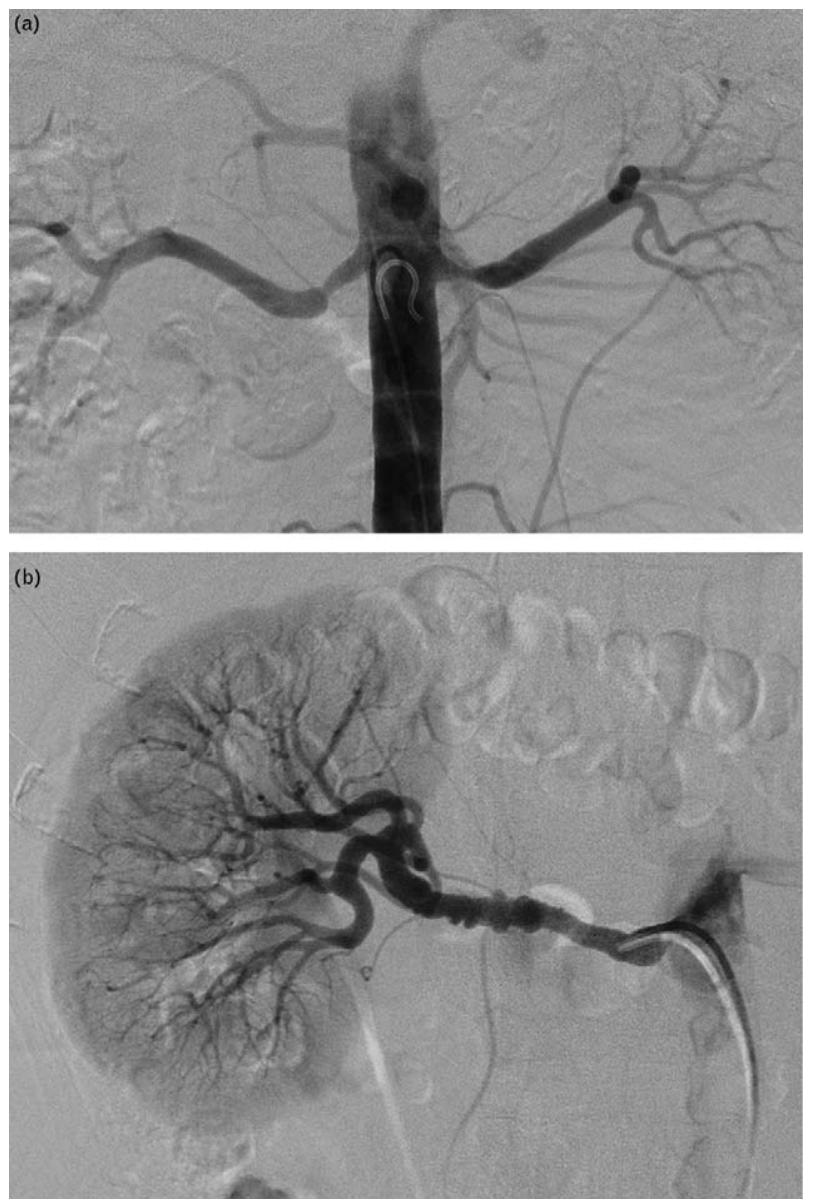

FIGURE 1 Unifocal and multifocal fibromuscular dysplasia. Digital subtraction angiographies, showing bilateral unifocal fibromuscular dysplasia (a) and multifocal fibromuscular dysplasia of the right renal artery (b, note the typical string-of-beads pattern).

unifocal FMD and compared these with those in patients with multifocal FMD.

\section{METHODS}

\section{Patients}

We prospectively collected data from all patients who underwent renal angiography in our hospital over the past two decades. Patients were referred for angiography in case of clinical suspicion on renovascular abnormalities. Reasons for this were early onset hypertension, difficult-to-treat hypertension, a decrease in renal function following treatment with an angiotensin-converting enzyme inhibitor or angiotensin II type-1-receptor blocker, or clinical clues for renal artery stenosis or FMD, such as an abdominal bruit or spontaneous dissection of a coronary or cervical artery $[10,11]$. All patients gave written informed consent.

\section{Protocol}

To avoid interference with the measurements all antihypertensive drugs were discontinued 3 weeks before the angiography. $\mathrm{BP}$ was monitored weekly, in case of an unacceptably large rise in BP patients were excluded from the study. We did not include patients with a high risk for acute cardiovascular events, predominantly in case of an expected large rise in BP after discontinuation of antihypertensive drugs or a cardiovascular event within 6 months prior to the angiography. To prevent suppression of renin secretion by high sodium intake, patients were instructed to follow a mildly sodium-restricted diet during the week prior to the angiography. The day preceding the angiography the patients were admitted to our ward, collected a 24-h urine specimen for measurement of sodium excretion as a marker for dietary sodium intake [12], and underwent 24-h ambulatory BP measurement (24-h ABPM, using SpaceLabs ambulatory BP monitor type 90207 or 90217 b (Spacelabs Healthcare, Snoqualmie, Washington, USA).

After an overnight fast, we selectively catheterized the aorta and both renal veins via the femoral route, without the use of contrast agents and under continuous monitoring of heart rate and BP (intra-arterially). Then, we drew blood samples from the aorta and both renal veins, followed by measurement of mean renal blood flow (MRBF, expressed as $\mathrm{ml} / 100 \mathrm{~g} \mathrm{kidney} / \mathrm{min}$ ) using the ${ }^{133}$ Xenon washout technique as previously described [13]. Briefly, we infused ${ }^{133}$ Xenon directly into the renal artery and recorded the washout of ${ }^{133}$ Xenon with an extracorporeal scintillation counter positioned at the kidney level. Exhaled ${ }^{133}$ Xenon was captured via a tight mask and led through a charcoal filter. After subtraction of background radiation, the washout of ${ }^{133}$ Xenon from the kidney was analyzed mathematically using an exponential decay model. From this model MRBF was calculated. In the majority of patients, MRBF was measured twice in each kidney. The mean of the two measurements was used for the analyses. In our hospital, ${ }^{133}$ Xenon washout technique has a variation coefficient of $8 \%$ for repeated measurements [14]. No contrast material was administered prior to completion of the blood sampling and ${ }^{133}$ Xenon washout studies. After completion of the ${ }^{133}$ Xenon washout procedure, we obtained angiographic images of the abdominal aorta and renal arteries (an anterior-posterior and two oblique views) by injection of $25 \mathrm{ml}$ of iopromide (Ultravist 300; Bayer HealthCare, Berlin, Germany) via a 4-Fr Universal Flush catheter (Cordis; Cardinal Health, Dublin, Ohio, USA) positioned at the level of the renal arteries. Selective renal angiography was performed with injection of 12-ml iopromide through a 5-Fr end-hole Cobra-2 or Simmons-2 catheter (Cordis; Cardinal Health). Finally, balloon angioplasty was performed if considered clinically indicated. The study was conducted in accordance with the Declaration of Helsinki and the protocol was approved by the Medical Ethics Committee of the Maastricht University Medical Centre.

The angiographic films were analyzed by two experienced, independent radiologists who were unaware of the results of the MRBF measurements. The patients were classified as having either no renal artery abnormalities, atherosclerotic renal artery stenosis (ARAS) or FMD. Based on their radiological appearance, FMD lesions were classified into unifocal (presence of a single focal stenosis less than $1 \mathrm{~cm}$ in the absence of atherosclerotic changes in the aorta or local calcifications on the angiography or previous imaging studies) or multifocal FMD (presence of more than two nonatherosclerotic stenoses with a typical string-ofbeads appearance in at least one renal artery, visible in at least two imaging planes) [4]. In case of disagreement on renal artery abnormalities, a third radiologists' opinion 
was decisive. In addition, all cases of unifocal FMD were retrospectively reviewed by two FMD experts (D.J.L.v.T. and A.A.K.), as it is sometimes difficult to distinguish unifocal FMD from atherosclerosis. In case of any doubt on the diagnosis of unifocal FMD, the patients were excluded from the present analyses $(n=9)$.

\section{Inclusion and exclusion criteria}

In the present analysis, we only included patients who were diagnosed with renal artery FMD between 2005 and 2017 and from whom a complete renal angiography and selective blood samples were available. The majority of patients with multifocal FMD were also included in a previous study on renal hemodynamics in multifocal FMD $[8,9]$. To avoid distortion of the results, we excluded patients with ARAS (with or without concomitant FMD), patients with low grade unifocal FMD (defined as a reduction in luminal diameter less than 50\% as measured with an electronic caliper), patients in whom renovascular abnormalities had been previously treated, patients with other secondary causes of hypertension, and patients who had only one kidney (congenital or acquired), a contracted kidney, a tumor of the kidney, syndromal disease (e.g. Marfan or Ehlers-Danlos), or inflammatory vascular diseases (such as Takayasu or giant-cell arteritis).

\section{Calculations and analyses}

We assessed renin secretion per individual kidney by measuring active plasma renin concentration (APRC, measured using an immunoradiometric assay) [15] in blood samples obtained from the aorta and both renal veins. We evaluated renin secretion in three different ways, all in accordance with previous literature:

1. Renal vein renin ratio: renal vein APRC of the affected kidney divided by renal vein APRC of the unaffected kidney (only in patients with unilateral FMD) [16].

2. Renin (venous - arterial)/arterial: the venous-arterial difference in APRC divided by the arterial APRC [17].

3. Renin secretion rate (RSR): the product of the venousarterial difference in APRC and the renal plasma flow [MRBF $\times(1-$ hematocrit $)]$ [18]. This method enabled us to calculate the net renin-production per $100 \mathrm{~g}$ of kidney tissue for each kidney.

We evaluated glomerular filtration rate per individual kidney by calculating a proxy for glomerular filtration per kidney (GFR) proxy by multiplying the filtration fraction (estimated by means of creatinine extraction) by the renal plasma flow according to the following formula: (renal artery creatinine level minus renal vein creatinine level divided by the renal artery creatinine level $) \times[\mathrm{MRBF} \times(1-$ hematocrit $)]$. Estimated glomerular filtration rate (eGFR) at baseline and during follow-up was estimated using the Chronic Kidney Disease Epidemiology Collaboration formula [19].

Although this study was not designed as an intervention study, we performed a post-hoc analysis to evaluate the BP response to balloon angioplasty. This was done to determine whether the FMD lesions truly played a role in causing hypertension or merely were an 'innocent bystander' (i.e. the patients had essential hypertension instead). As previously mentioned, not all patients underwent balloon angioplasty as this was only performed if considered clinically indicated. According to previous literature (the Rundback criteria) [20], a response was defined as a reduction in DBP at least $15 \mathrm{mmHg}$, a SBP $140 \mathrm{mmHg}$ or less, and/or a DBP $90 \mathrm{mmHg}$ or less (mean of the second and last measurement of three office BP measurements with 1-min intervals) 1 year after balloon angioplasty without an increase in the number of antihypertensive drugs (evaluated using WHO's Defined Daily Doses classification) [21].

We used SPSS (SPSS Inc., version 23.0, Chicago, Illinois, USA) and Graphpad (Graphpad Software Inc., version 5.01, San Diego, California, USA) for the statistical analyses. $t$ Tests (paired and unpaired) were used for normally distributed data (expressed as mean \pm SD) and Wilcoxon signed rank test and Mann-Whitney $U$ test for nonnormally distributed data (expressed as medians and interquartile range). Chi-square test was used to assess categorical data and correlation was tested using Pearsons $R$. A $P$ value of less than 0.05 was considered statistically significant.

\section{RESULTS}

\section{Patient characteristics}

Altogether, 101 patients with renal artery FMD were included: 26 with unifocal FMD and 75 with multifocal FMD (all white). As shown in Table 1, multifocal FMD was most often bilateral $(n=33)$ or right-sided $(n=34)$, whereas unifocal FMD was more equally distributed between left $(n=12)$ and right $(n=10)(P<0.001)$. Only four patients were diagnosed with bilateral unifocal FMD. Therefore, comparisons with this small group are of limited value. None of the study participants had to be excluded from the study because of unacceptably high $\mathrm{BP}$ and no acute cardiovascular events were reported during the study.

We observed no statistically significant differences between the two FMD subtypes for age, age of onset of hypertension, smoking behavior, BP, and 24-h urinary sodium intake. eGFR, however, was significantly lower in unifocal FMD as compared with multifocal FMD $\left(66.8 \pm 24.1\right.$ vs. $82.6 \pm 19.0 \mathrm{ml} / \mathrm{min}$ per $\left.1.73 \mathrm{~m}^{2} ; P=0.001\right)$.

\begin{tabular}{|lcc|}
\hline TABLE 1. Patient characteristics & & \\
\hline Characteristic & Unifocal & Multifocal \\
\hline$n$ & 26 & 75 \\
\hline Right/left/bilateral, $n$ & $10 / 12 / 4$ & $34 / 8 / 33^{*}$ \\
\hline Sex (male/female) & $10 / 16$ & $19 / 56$ \\
\hline Age (years) & $50.0 \pm 12.4$ & $54.0 \pm 10.5$ \\
\hline Age of onset of hypertension (years) & $42.1 \pm 11.4$ & $41.1 \pm 13.7$ \\
\hline BMl (kg/m²) & $26.4 \pm 4.3$ & $26.5 \pm 4.5$ \\
\hline Diabetes mellitus (yes/no) & $4 / 26$ & $5 / 70$ \\
\hline Current smoking (yes/no) & $9 / 17$ & $18 / 56$ \\
\hline 24-h SBP (mmHg) off medication & $160 \pm 21$ & $156 \pm 24$ \\
\hline 24-h DBP (mmHg) off medication & $97 \pm 12$ & $92 \pm 18$ \\
\hline eGFR (ml/min per $1.73 \mathrm{~m}^{2}$ ) & $66.8 \pm 24.1$ & $82.6 \pm 19.0^{* *}$ \\
\hline Urinary sodium excretion (mmol/24h) & $77 \pm 55$ & $88 \pm 51$ \\
\hline
\end{tabular}

Characteristics of the study patients. Values expressed as mean \pm SD or absolute number eGFR, estimated glomerular filtration rate using the Chronic Kidney Disease Epidemiology Collaboration formula [19]; FMD, fibromuscular dysplasia.

${ }^{*} P<0.001$ vs. unifocal FMD.

${ }^{* *} P=0.001$ vs. unifocal FMD. 
(a)

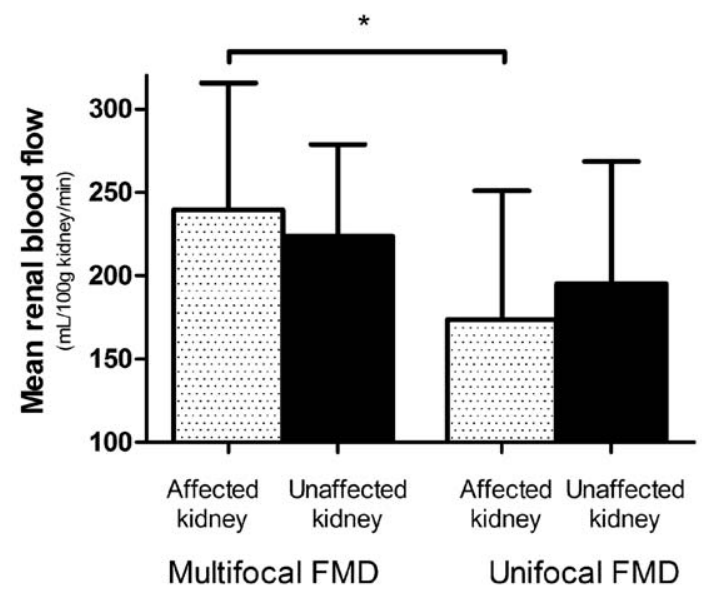

(b)

Bilateral

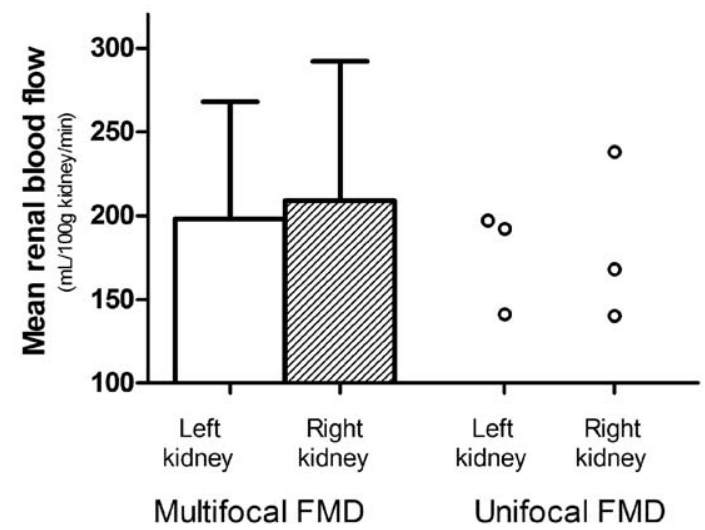

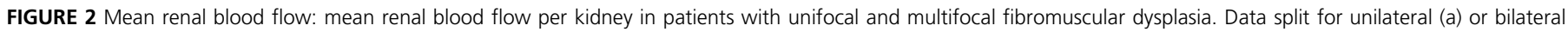

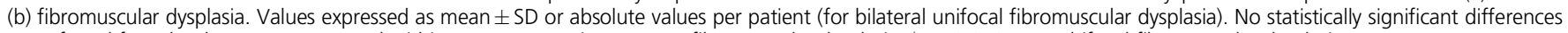
were found for other between-group and within-group comparisons. FMD, fibromuscular dysplasia. ${ }^{*} P=0.013$ vs. multifocal fibromuscular dysplasia.

\section{Renal blood flow and glomerular filtration}

As shown in Fig. 2, MRBF of the affected kidney in patients with unilateral FMD was significantly lower in unifocal FMD as compared with multifocal FMD (mean $173 \pm 77$ vs. $244 \pm 79 \mathrm{ml} / 100 \mathrm{~g}$ kidney $/ \mathrm{min} ; P=0.013)$. The difference in MRBF between unifocal and multifocal FMD for the unaffected kidney was not statistically significant, although a trend was observed as well ( $195 \pm 73 \mathrm{vs} .225 \pm 54 \mathrm{ml} / 100 \mathrm{~g}$ kidney/min; $P=\mathrm{NS}$ ). Such trend was also observed with regard to MRBF in unilateral unifocal FMD, with a lower MRBF in the affected kidney as compared with the nonaffected kidney $(173 \pm 77 \mathrm{vs} .195 \pm 73 \mathrm{ml} / 100 \mathrm{~g}$ kidney/min $P=\mathrm{NS}$ ). Among patients with bilateral multifocal FMD, MRBF did not significantly differ between the left and right kidney (left $201 \pm 69$ and right $209 \pm 85 \mathrm{ml} / 100 \mathrm{~g}$ kidney/ min; $P=$ NS). From nine patients with unifocal FMD and 16 patients with multifocal FMD, MRBF could not be obtained due unavailability of ${ }^{133}$ Xenon or technical problems with the administration of ${ }^{133}$ Xenon such as difficulties in advancing the catheter into the renal artery or patient's intolerance of wearing the mask that prevents spreading of exhaled ${ }^{133}$ Xenon into the room.

As shown in Fig. 3, GFR proxy $_{\text {in }}$ patients with unilateral FMD was lower in unifocal as compared with multifocal FMD for both the affected $(38 \pm 28$ vs. $19 \pm 27 \mathrm{ml} / 100 \mathrm{~g}$ kidney/min; $P=0.008)$ and unaffected kidney $(40 \pm 22$ vs. $21 \pm 24 \mathrm{ml} / 100 \mathrm{~g}$ kidney $/ \mathrm{min} ; P=0.014)$. No clear trend towards lateralization of $\mathrm{GFR}_{\text {proxy }}$ was observed between the affected and unaffected kidney in both groups $(P=\mathrm{NS})$. Among patients with bilateral multifocal FMD, GFR proxy $_{\text {was }}$ significantly higher in the right kidney as compared with the left ( $47 \pm 22$ vs. $34 \pm 23 \mathrm{ml} / 100 \mathrm{~g}$ kidney/min; $P=0.008$ ). (a)

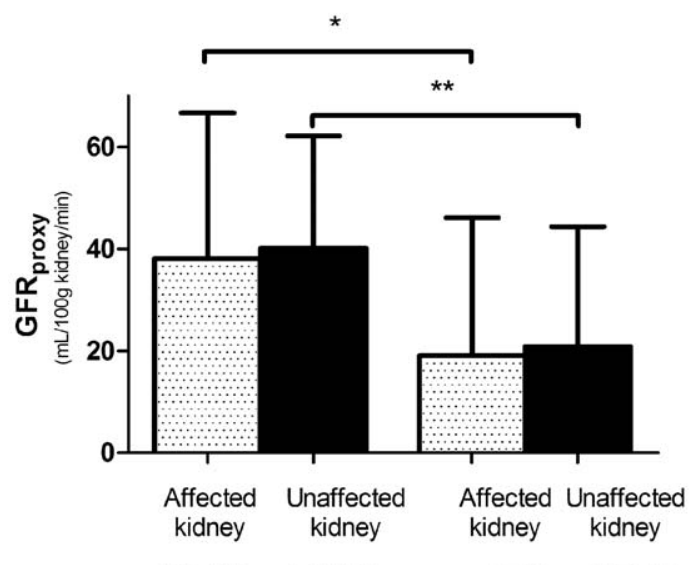

(b)

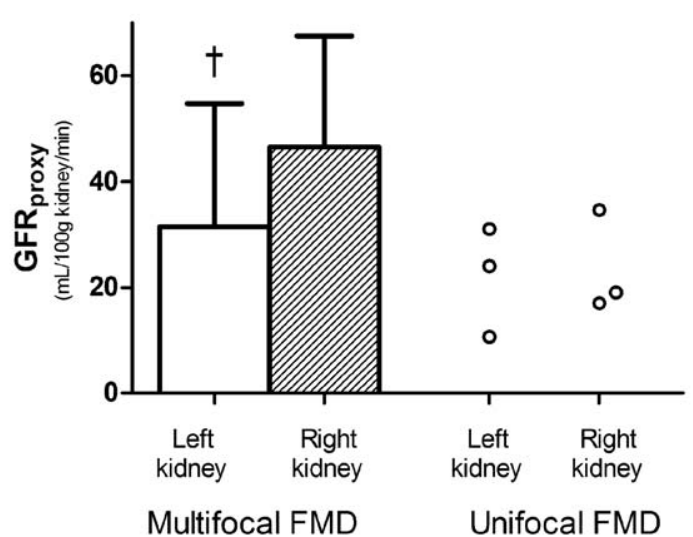

FIGURE 3 A proxy for glomerular filtration per kidney: a proxy for glomerular filtration per kidney for each kidney in patients with unifocal and multifocal fibromuscular dysplasia. Data split for unifocal and bilateral fibromuscular dysplasia and expressed as mean \pm SD or absolute values per patient (for bilateral unifocal fibromuscular dysplasia). FMD, fibromuscular dysplasia; GFR $R_{\text {proxy, }}$ a proxy for glomerular filtration per kidney. ${ }^{*} P=0.008$ and ${ }^{* * *} P=0.014$ vs. unifocal fibromuscular dysplasia, ${ }^{* * *} P=0.008$ vs. right kidney. 
TABLE 2. Renin-secretion

\begin{tabular}{|c|c|c|c|c|c|}
\hline Group & $\begin{array}{l}\text { Arterial renin } \\
\text { level (mU/l) }\end{array}$ & $\begin{array}{l}\text { Renin (venous - arterial)/ } \\
\text { arterial nonaffected } \\
\text { or left kidney }\end{array}$ & $\begin{array}{l}\text { Renin (venous - arterial)/ } \\
\text { arterial affected } \\
\text { or right kidney }\end{array}$ & $\begin{array}{l}\text { RSR nonaffected } \\
\text { or left kidney } \\
\text { (mU/100g kidney/min) }\end{array}$ & $\begin{array}{c}\text { RSR affected } \\
\text { or right kidney } \\
\text { (mU/100 g kidney/min) }\end{array}$ \\
\hline \multicolumn{6}{|l|}{ Unilateral } \\
\hline Unifocal & $16.7(12.6-35.4)$ & $0.11(0.00-0.22)$ & $0.26(0.03-0.40)$ & $0.32(-0.02-0.81)$ & $0.46(0.02-1.02)$ \\
\hline Multifocal & $21.0(11.8-32.1)$ & $0.15(0.01-0.29)$ & $0.17(0.07-0.33)$ & $0.36(0.03-0.79)$ & $0.40(0.09-0.80)$ \\
\hline \multicolumn{6}{|l|}{ Bilateral } \\
\hline Unifocal & $56.5(21.2-70.8)$ & $0.16(0.05-0.71)$ & $0.05(0.00-0.11)$ & $0.34(0.22-0.90)$ & $0.14(0.10-0.26)$ \\
\hline Multifocal & $19.8(10.2-36.4)$ & $0.12(0.01-0.19)$ & $0.16(0.00-0.35)$ & $0.24(0.00-0.99)$ & $0.35(0.03-0.96)$ \\
\hline
\end{tabular}

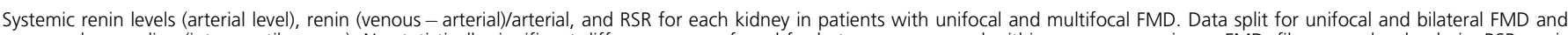

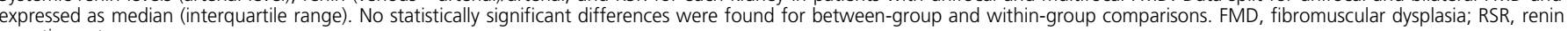
secretion rate.

\section{Renin secretion}

Renin secretion was evaluated in three different ways. Renal vein renin ratio (cutoff $\geq 1.5$ based on previous literature) [16] was positive in two out of 22 patients with unilateral unifocal FMD (mean 1.07; range 0.73-2.13), but below cutoff in all patients with unilateral multifocal FMD (mean 1.02; range $0.76-1.48 ; P=$ NS for between group comparison). Renin (venous - arterial)/arterial (cutoff $\geq 0.48$ based on previous literature) [17] was positive in three out of 22 patients with unilateral unifocal FMD, but below cutoff in all patients with unilateral multifocal FMD (Table 2). In unilateral unifocal FMD, a trend towards increased renin secretion in the affected kidney as compared with the unaffected kidney was observed [for both renin (venous - arterial)/arterial and RSR; Table 2], but this difference was not statistically significant. In patients with bilateral FMD, renin secretion was comparable between both groups. As shown in Fig. 4 , a negative correlation ( $\beta$ $-0.407, P<0.001)$ was found between renin levels and $24-$ h SBP (during 24-h ABPM) in patients with multifocal FMD. In unifocal FMD, however, no statistically significant correlation was observed $(\beta 0.118, P=0.620)$.

\section{Blood pressure response to balloon angioplasty} In a post-hoc analysis we found a reduction in BP (according to the Rundback criteria [20] and a stable or lower number of antihypertensive drugs) 1 year after balloon angioplasty in $76 \%$ of patients with unifocal FMD and $54 \%$ of patients with multifocal FMD $(P=$ NS, Supplemental
Table 1, http://links.lww.com/HJH/A931). For both groups, no statistically significant differences in patient characteristics were observed between responders and nonresponders. However, in patients with unifocal FMD a (nonstatistically significant) trend was observed towards higher renin (venous - arterial/arterial) in the responders as compared with the nonresponders [0.24 (0.05-0.42) vs. 0.06 (0.00-0.29); $P=$ NS).

\section{DISGUSSION}

The main finding of our study is that renal blood flow and glomerular filtration are lower in kidneys with unifocal FMD as compared with those with multifocal FMD. Moreover, increased renin secretion was only observed in a subset of patients with unifocal FMD, but not in any of the patients with multifocal FMD. We studied this by comparing a cohort of patients with unifocal FMD to a cohort of patients with multifocal FMD, prior to balloon angioplasty and without antihypertensive drugs. Both groups were comparable with regard to patient characteristics such as age, duration of hypertension, BP, and dietary sodium intake. This was rather unexpected, as a previous cohort study found that patients with unifocal FMD are generally younger upon diagnosis (26 vs. 40 years), more often male, and have higher BP [4]. Although we have no good explanation for the absence of such differences in our cohort, this did enable us to study differences in renal perfusion and renin secretion without statistical corrections for differences in patient characteristics. (a) Multifocal FMD

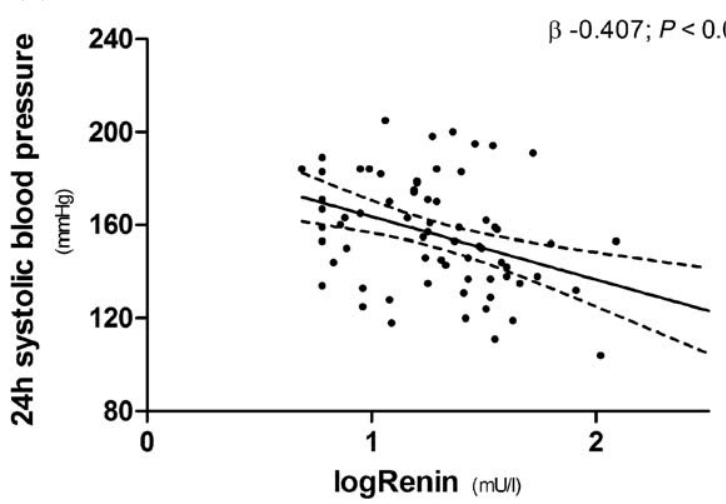

(b)

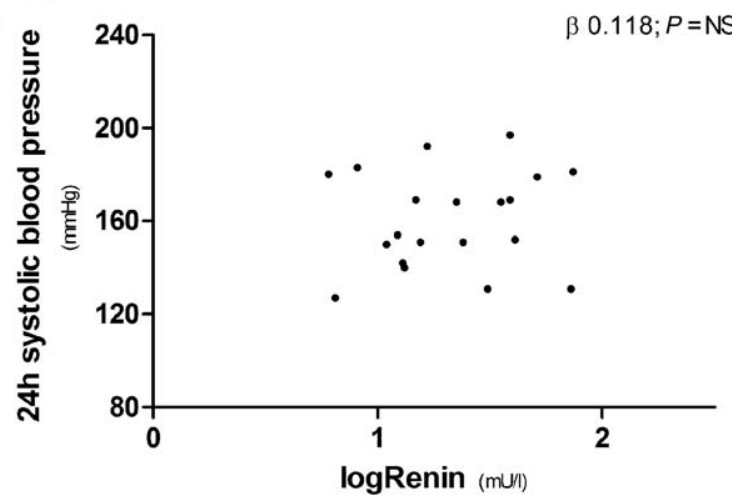

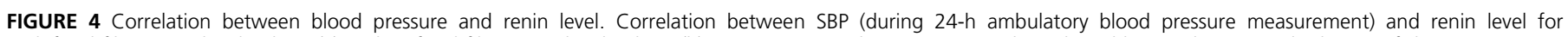

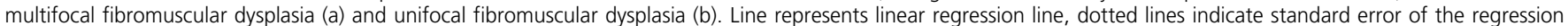
line. FMD, fibromuscular dysplasia. 
The present data demonstrate that the effect of unifocal FMD lesions on renal perfusion and glomerular filtration is more pronounced than that of multifocal FMD. As we previously demonstrated, intrarenal microvascular vascular function is relatively preserved in multifocal FMD, as renal perfusion, glomerular filtration, and the ability to respond to vasoactive substances are comparable with that in matched hypertensive patients without renovascular abnormalities [8]. In kidneys with unifocal FMD, however, renal blood flow and glomerular filtration are substantially reduced, indicating that its impact on the kidney is more severe. Renin secretion was only increased in a subset of patients with unifocal FMD, but not in any of the patients with multifocal FMD. Although only a few patients with unilateral unifocal FMD met the rather stringent cutoff values for renin (venous - arterial)/arterial and renal vein renin ratio $[16,17]$, we observed a trend towards higher renin (venous - arterial)/arterial and RSR in the affected kidney as compared with the unaffected kidney in the whole group of unifocal FMD patients, whereas no clues for such trend were observed in unilateral multifocal FMD. Admittedly, this trend was not statistically significant, but that is presumably due to a lack of power. Therefore, this trend could indicate that at least some lateralization in renin secretion occurs in unilateral unifocal FMD.

Thus, it appears that unifocal FMD induces a more 'classic' pattern of renovascular hypertension (at least in a subset of patients), with a reduction in renal perfusion that (subsequently) leads to increased renin secretion in the affected kidney, resembling the effect of renal artery clipping (in animal models) and renovascular hypertension due to ARAS [9,22]. In all probability, this is the result of a major disturbance in local renal artery hemodynamics due to the unifocal FMD lesion itself, which is supported by the large effect of balloon angioplasty on BP in these patients $[4,7]$. The (nonstatistically significant) trend that patients with unifocal FMD who did have a BP response to balloon angioplasty have higher renin (venous - arterial/arterial) as compared those who did not (Supplemental Table 1, http:// links.lww.com/HJH/A931) may further support this hypothesis. However, it has to be mentioned that data on the impact of FMD lesions on local intravascular hemodynamics in the renal artery (for example on the transstenotic pressure gradient) are still lacking. Regrettably, this was not part of our study protocol either. Therefore, the question remains to what extent renal perfusion is reduced due to the local hemodynamic impact of the FMD lesion itself and to what extent this is the result of intrarenal microvascular damage due to longstanding hypertension. Our observation that glomerular filtration is also reduced in the nonaffected kidney in unilateral FMD may be supportive for contribution of the latter as well. However, as unifocal and multifocal FMD were not different with respect to $\mathrm{BP}$ or duration of hypertension this does not explain the quite large differences in $\mathrm{GFR}_{\text {proxy }}$ between unifocal and multifocal FMD in the nonaffected kidney, suggesting that other yet unknown factors contribute to the renal damage in unifocal FMD.

In multifocal FMD, it appears less likely that hypertension is caused by a reduction in renal perfusion, and, subsequently increased renin secretion. Apart from the findings that renal blood flow is relatively preserved and that local renin secretion was not increased (in any of the 75 patients), the association between renin levels and $\mathrm{BP}$ in patients with multifocal FMD is negative, which is inverse to what one would expect in the case of 'classical' renovascular hypertension. One could argue that these patients may in fact have essential hypertension, in other words that the string-of-beads is merely an 'innocent bystander' that is not related to hypertension $[1,2]$. However, in the post-hoc analysis to evaluate the response to balloon angioplasty, we found that $54 \%$ of the multifocal FMD patients in our cohort had a substantial decrease in BP. These numbers are presumably even underestimated as many patients were per definition nonresponder, while a clear clinical improvement was observed (for example patients in whom BP was already well regulated, but in whom the number of antihypertensive drugs could be markedly reduced after balloon angioplasty or patients who had a slight increase in the number of antihypertensive drugs, but a large reduction in $\mathrm{BP})$. These data as well as several other observational studies that reported a beneficial effect of balloon angioplasty in many patients with multifocal FMD (without data on renal perfusion, renin secretion, or trans-stenotic pressure gradient) [7] indicate that the string-of-beads in at least in those patients contributed to high BP, instead of only being an 'innocent bystander'. Nevertheless, renal perfusion in those kidney is relatively preserved and the stringof-beads apparently does not lead to increased renin secretion or activation of the intrarenal renin-angiotensin system [8], suggesting a different pathophysiological mechanism.

Therefore, future studies are needed to answer the questions why patients with multifocal FMD develop and maintain hypertension and why BP decreases after balloon angioplasty. Such (prospective) studies should focus on changes before and after balloon angioplasty, particularly on other alterations in intrarenal hemodynamics aside from perfusion alone (such as wall stress, turbulence of blood flow, and pulse wave transmission), but also on changes in other signaling pathways involved in hypertension such as the sympathetic nervous system, reactive oxygen species, and various autocrine and paracrine signaling systems next to the renin-angiotensin system.

The current study is obviously limited by its low statistical power, especially with regard to the low number of patients with bilateral unifocal FMD. However, taking into account the low incidence of unifocal FMD and the rather stringent exclusion criteria (inability to discontinue antihypertensive drugs, previous balloon angioplasty, etc.), this is quite a large series for such an invasive study. An unavoidable limitation is the absence of a gold standard for the diagnosis of unifocal FMD. However, as we critically reviewed all the cases of unifocal FMD and excluded all cases with any doubt on the diagnosis of unifocal FMD (especially clues for ARAS), we consider the risk of incorrect inclusion to be low. The post-hoc analysis on the effect of balloon angioplasty was limited by selection bias as this was only performed if the treating physician considered this clinically indicated. The same (inevitably) holds true for selecting the patients who were referred for angiography. However, as digital subtraction angiography is the gold standard in the case of suspicion for renovascular 
abnormalities, this is used as the first-line imaging technique in our hospital. Hence, almost all patients who were diagnosed with renal artery FMD in our hospital were included in this study. Regrettably, measurement of the trans-stenotic pressure gradient was not part of our standard protocol as this was not common routine at the time the study was initiated (two decades ago). Although experts suggested that such measurements may be able to differentiate between patients with hypertension due to FMD and those with essential hypertension in whom FMD in merely an 'innocent bystander', we would like to emphasize that its value has only been established in patients with ARAS $[23,24]$ and not yet in FMD. In the current study, a BP response to balloon angioplasty was observed in the majority of patients, indicating that FMD contributed to hypertension at least in those patients and was more than only an 'innocent bystander'. Nevertheless, measurement of transstenotic pressure gradients would have provided interesting additional information to the current study. Therefore, future studies should certainly consider measuring transstenotic pressure gradient as well.

In conclusion, we found that renal blood flow and glomerular filtration were substantially lower in kidneys with unifocal FMD as compared with multifocal FMD. Moreover, increased renin secretion was only observed in a subset of patients with unifocal FMD, but not in any of the patients with multifocal FMD. These findings suggest that the impact of unifocal FMD lesions on the kidney is more severe, resulting in a 'classic' pattern of renovascular hypertension, resembling the effect of renal artery clipping and renovascular hypertension due to ARAS. In multifocal FMD, however, this appears not to be the case as renal blood flow is more preserved, local renin secretion is not increased, and the association between renin levels and BP is inverse. These differences in effect on the kidney may explain the often more severe clinical presentation and higher success rate of revascularization in patients with unifocal FMD but also suggest that that the pathophysiological mechanisms leading to hypertension may differ between these two disease entities. To unravel the exact pathophysiological mechanisms leading to hypertension in multifocal FMD, future studies focusing on changes before and after balloon angioplasty are needed.

\section{ACKNOWLEDGEMENTS}

We wish to thank the Department of Radiology of our hospital for reviewing the radiographic films and Mrs C. de Haan for collecting and handling the blood samples.

\section{Conflicts of interest}

There are no conflicts of interest.

\section{REFERENGES}

1. Persu A, Van der Niepen P, Touze E, Gevaert S, Berra E, Mace P, et al. Revisiting fibromuscular dysplasia: rationale of the European fibromuscular dysplasia initiative. Hypertension 2016; 68:832-839.

2. Olin JW, Gornik HL, Bacharach JM, Biller J, Fine LJ, Gray BH, et al. Fibromuscular dysplasia: state of the science and critical unanswered questions: a scientific statement from the American Heart Association. Circulation 2014; 129:1048-1078.

3. Olin JW. Is fibromuscular dysplasia a single disease? Circulation 2012; 126:2925-2927.
4. Savard S, Steichen O, Azarine A, Azizi M, Jeunemaitre X, Plouin PF. Association between 2 angiographic subtypes of renal artery fibromuscular dysplasia and clinical characteristics. Circulation 2012; 126:3062-3069.

5. Varennes L, Tahon F, Kastler A, Grand S, Thony F, Baguet JP, et al. Fibromuscular dysplasia: what the radiologist should know: a pictorial review. Insights Imaging 2015; 6:295-307.

6. Harrison EG Jr, Hunt JC, Bernatz PE. Morphology of fibromuscular dysplasia of the renal artery in renovascular hypertension. Am J Med 1967; 43:97-112.

7. Trinquart L, Mounier-Vehier C, Sapoval M, Gagnon N, Plouin PF. Efficacy of revascularization for renal artery stenosis caused by fibromuscular dysplasia: a systematic review and meta-analysis. Hypertension 2010; 56:525-532.

8. van Twist DJ, Houben AJ, de Haan MW, de Leeuw PW, Kroon AA. Renal hemodynamics and renin-angiotensin system activity in humans with multifocal renal artery fibromuscular dysplasia.J Hypertens 2016; 34:1160-1169

9. van Twist DJ, Houben AJ, de Haan MW, de Leeuw PW, Kroon AA. Pathophysiological differences between multifocal fibromuscular dysplasia and atherosclerotic renal artery stenosis. J Hypertens 2017; 35:845-852

10. Saw J, Bezerra H, Gornik HL, Machan L, Mancini GB. Angiographic and intracoronary manifestations of coronary fibromuscular dysplasia. Circulation 2016; 133:1548-1559.

11. Kadian-Dodov D, Gornik HL, Gu X, Froehlich J, Bacharach JM, Chi YW, et al. Dissection and aneurysm in patients with fibromuscular dysplasia: findings from the U.S. Registry for FMD. J Am Coll Cardiol 2016; 68:176-185.

12. Kesteloot H, Joossens JV. The relationship between dietary intake and urinary excretion of sodium, potassium, calcium and magnesium: Belgian Interuniversity Research on Nutrition and Health. J Hum Hypertens 1990; 4:527-533.

13. van Twist DJ, Houben AJ, de Haan MW, Mostard GJ, Kroon AA, de Leeuw PW. Angiotensin-(1-7)-induced renal vasodilation in hypertensive humans is attenuated by low sodium intake and angiotensin II coinfusion. Hypertension 2013; 62:789-793.

14. Wierema TK, Houben AJ, Kroon AA, Koster D, van der Zander K, van Engelshoven JM, et al. Nitric oxide dependence of renal blood flow in patients with renal artery stenosis. J Am Soc Nephrol 2001; 12:18361843.

15. Deinum J, Derkx FH, Schalekamp MA. Improved immunoradiometric assay for plasma renin. Clin Chem 1999; 45 (6 Pt 1):847-854.

16. Luscher TF, Vetter H, Studer A, Pouliadis G, Kuhlmann U, Glanzer K, et al. Renal venous renin activity in various forms of curable renal hypertension. Clin Nephrol 1981; 15:314-320.

17. Luscher TF, Greminger P, Kuhlmann U, Siegenthaler W, Largiader F, Vetter W. Renal venous renin determinations in renovascular hypertension. Diagnostic and prognostic value in unilateral renal artery stenosis treated by surgery or percutaneous transluminal angioplasty. Nephron 1986; 44 (Suppl 1):17-24.

18. Blaufox MD, Fromowitz A, Lee HB, Mend CH, Elkin M. Renal blood flow and renin activity in renal venous blood in essential hypertension. Circ Res 1970; 27:913-920.

19. Levey AS, Stevens LA, Schmid CH, Zhang YL, Castro AF3rd, Feldman HI, et al. A new equation to estimate glomerular filtration rate. Ann Intern Med 2009; 150:604-612.

20. Rundback JH, Sacks D, Kent KC, Cooper C, Jones D, Murphy T, et al. Guidelines for the reporting of renal artery revascularization in clinical trials. American Heart Association. Circulation 2002; 106:1572-1585.

21. WHO Collaborating Centre for Drug Statistics Methodology. Guidelines for ATC classification and DDD assignment, 2018. Oslo; 2018. https://www.whocc.no/filearchive/publications/guidelines.pdf.

22. Textor SC, Lerman L. Renovascular hypertension and ischemic nephropathy. Am J Hypertens 2010; 23:1159-1169.

23. De Bruyne B, Manoharan G, Pijls NH, Verhamme K, Madaric J, Bartunek $\mathrm{J}$, et al. Assessment of renal artery stenosis severity by pressure gradient measurements. J Am Coll Cardiol 2006; 48:18511855.

24. Mangiacapra F, Trana C, Sarno G, Davidavicius G, Protasiewicz M, Muller $\mathrm{O}$, et al. Translesional pressure gradients to predict blood pressure response after renal artery stenting in patients with renovascular hypertension. Circ Cardiovasc Interv 2010; 3:537-542. 